\title{
Чаулин А.М.
}

\section{Новые биомаркеры для стратификации риска сердечно-сосудистых заболеваний}

Самарский государственный медицинский университет Самарский областной клинический кардиологический диспансер (Россия, Самара)

doi: $10.18411 / \mathrm{j}-10-2020-32$

idsp: ljournal-10-2020-32

\section{Аннотация}

Боль в груди и другие симптомы, которые могут указывать на острый коронарный синдром (ОКС), являются частыми причинами обращений в отделения неотложной помощи. Из-за высокого уровня заболеваемости, смертности и ответственности, связанных как с признанной, так и с нераспознанной сердечнососудистой патологией, агрессивный подход к оценке этой группы пациентов стал стандартом лечения. Исторически биомаркеры играли значительную роль в диагностике и стратификации риска ряда сердечно-сосудистых заболеваний (СС3), включая инфаркт миокарда, застойную сердечную недостаточность и тромбоэмболию легочной артерии. Целью этого обзора будет обсуждение этих новых биомаркеров и описание их потенциальной роли для стратификации риска пациентов с СС3.

Ключевые слова. биомаркеры, лабораторная диагностика, сердечно-сосудистые заболевания, стратификация риска, инфаркт миокарда, сердечная недостаточность, сердечные тропонины, PCSK-9, окисленный липопротеин низкой плотности, натрийуретический пептид.

\section{Abstract}

Chest pain and other symptoms that may indicate acute coronary syndrome (ACS) are common causes of emergency Department visits. Due to the high incidence, mortality, and liability associated with both recognized and unrecognized cardiovascular diseases, an aggressive approach to evaluating this group of patients has become the standard of care. Historically, biomarkers have played a significant role in the diagnosis and risk stratification of a number of cardiovascular diseases (CVD), including myocardial infarction, congestive heart failure, and pulmonary embolism. The purpose of this review is to discuss these new biomarkers and describe their potential role for risk stratification in patients with CVD.

Keywords. biomarkers, laboratory diagnostics, cardiovascular diseases, risk stratification, myocardial infarction, heart failure, cardiac troponins, PCSK-9, oxidized lowdensity lipoprotein, natriuretic peptide.

\section{Введение.}

Сердечно-сосудистые заболевания являются одними из ведущих причин смертности и инвалидизации населения. Лабораторная диагностика сердечнососудистых заболеваний является актуальным направлением, поскольку она является одним из ключевых методов верификации диагноза $[1,2,3,4,5]$.

Изучение новых биомаркеров должно включать валидацию аналитической погрешности и пределов обнаружения, характеристику калибратора, специфичность и стандартизацию анализа, преаналитические вопросы и соответствующие исследования референсных интервалов $[5,6,7,8,9,10]$. Идеальный биомаркер должен помочь врачу в диагностике, прогнозе и лечении.

Интерес к воспалительным биомаркерам является результатом растущего понимания воспаления как ключевой части патофизиологической последовательности в развитии как ишемической болезни сердца (ИБС), так и ОКС $[1,11,12,13,14]$.

\section{Воспалительные биомаркеры}


Окисленный липопротеин низкой плотности (oxLDL). Воспаление в атеросклеротической бляшке имеет решающее значение для патофизиологии инфаркта миокарда, и окисленный липопротеин низкой плотности (oxLDL), как полагают, является ключевым медиатором этого процесса. OxLDL является провоспалительным медиатором, который сильно коррелирует с неблагоприятными сердечно-сосудистыми событиями. Вызывая местное воспаление в атеросклеротической бляшке, oxLDL приводит к эндотелиальной дисфункции, расширению бляшки за счет образования пенистых клеток, дестабилизации бляшки и, в конечном итоге, к разрыву бляшки, ведущему к инфаркту миокарда $[15,16,17,18]$.

Матричная металлопротеиназа (ММП). Микроскопическое исследование атеросклеротической бляшки (как коронарной, так и аортальной) у людей продемонстрировало избыточную активность по разложению матрикса, предполагая, что повышенные уровни матричной металлопротеиназы (ММП) могут действовать как суррогатный маркер бремени атеросклеротических бляшек [19, 20, 21].

Лейкоцитарный фермент миелопероксидаза (МПО). МПО секретируется во время острого воспаления и вызывает окисление липопротеинов, что связано с наличием коронарной болезни. Что еще более важно, высокие уровни МПО могут также предсказывать наличие острого коронарного синдрома у пациентов с болью в груди $[23,24,25]$.

Липопротеин-ассоциированная фосфолипаза A2. Липопротеинассоциированная фосфолипаза A2 (Lp-PLA2), фермент, в основном вырабатываемый моноцитами и макрофагами, генерирует мощные провоспалительные продукты. Субэндотелиальное окисление липопротеинов низкой плотности (ЛПНП) рассматривается как очень важный биологический процесс, который как инициирует, так и ускоряет развитие поражения артерий [26, 27, 28].

\section{Маркеры некроза кардиомиоцитов}

Тропонин. В последние годы тропонин стал золотым стандартом в обнаружении инфаркта миокарда по сравнению со своими предшественниками, креатинфосфокиназой-МВ изоформой, миоглобином, и аспартатаминотрансферазой. Его эффективность в диагностике инфаркта миокарда хорошо подтверждена. По мере совершенствования методов тестирования было установлено превосходство сердечного тропонина I (cTnI) над сердечным тропонином $\mathrm{T}$ (cTnT), и по мере увеличения чувствительности каждого теста специфичность для острого коронарного синдрома подвергалась все большему сомнению $[10,11,15,20]$.

Хотя роль тропонина в идентификации инфаркта миокарда была четко установлена, его использование для выявления и прогнозирования при легочной эмболии становится потенциальным инструментом лечения легочной $[20,21,22,23$, 24].

Натрийуретический пептид (BNP). Измерение уровня натрийуретического пептида (BNP) первоначально изучалось как инструмент для дифференциации сердечных и внесердечных причин одышки. Впоследствии BNP также продемонстрировал некоторую полезность в качестве прогностического маркера инфаркта миокарда и сердечной недостаточности [25, 26, 27, 28, 29].

\section{Маркеры системы гемостаза}

D-димер. После образования сгустка фибринолиз указанного сгустка приводит к образованию продуктов расщепления фибрина, в частности D-димера. Полезность этого белкового фрагмента была хорошо подтверждена в прошлом для исключения тромбоэмболии легочной артерии (ТЭЛА) или тромбоза глубоких вен (ТГВ) у пациентов с низкой или средней вероятностью предварительного тестирования. Совсем недавно роль D-димера была дополнительно установлена в условиях расслоения аорты, а также в формировании тромбов, локализованных при ПЭ, а также в прогнозе [30, 31, $32,33,34]$. 
Фибриноген. Поскольку несоответствующий гемостаз может неожиданно привести к коронарному тромбозу, повышенные уровни определенных факторов свертывания крови могут быть связаны с будущими тромботическими событиями. Повышенные уровень фибриногена у пациентов с инфарктом миокарда свидетельствует о неблагоприятном прогнозе [34, 35, 36, 37].

Фактор Фон Виллебранда (vWF). Поскольку активация тромбоцитов тесно связана с тромбозом во время ОКС, логично предположить, что маркеры активации тромбоцитов могут быть полезны для прогнозирования результатов после ОКС [39, 40, 41]. В прошлом фактор фон Виллебранда (vWF) изучался как маркер потенциального выбора лечения и терапевтической мишени. Кроме того, его потенциал был исследован как средство прогнозирования неблагоприятных исходов.

Заключение. Поскольку количество сердечно-сосудистых биомаркеров растет, очень важно понимать сильные и слабые стороны каждого из них. Кроме того, очень важно, чтобы все биомаркеры не использовались как отдельные тесты. Они должны интерпретироваться в соответствующем клиническом контексте и не заменяют другие части обследования, такие как физикальное обследование или методы визуализации.

$$
\text { *** }
$$

1. Чаулин А.М. Некоторые современные биомаркеры сердечно-сосудистых заболеваний // Евразийское научное объединение. 2020. 7-3 (65): 199-202. https://elibrary.ru/item.asp?id=43840128

2. Чаулин А.М., Карслян Л.С., Григорьева Е.В., Нурбалтаева Д.А., Дупляков Д.В. Клиникодиагностическая ценность кардиомаркеров в биологических жидкостях человека // Кардиология. 2019;59(11):66-75. DOI:10.18087/cardio.2019.11.n414.

3. Chaulin A.M., Duplyakov D.V. MicroRNAs in Atrial Fibrillation: Pathophysiological Aspects and Potential Biomarkers // International Journal of Biomedicine. 2020;10(3):198-205. DOI: 10.21103/Article10(3)_RA3. http://ijbm.org/v10i3_4.htm

4. Чаулин А.М. Клинико-диагностическое значение определения кардиальных тропонинов в крови при сепсисе (обзор литературы) // The scientific heritage. 2020. 46-3 (46): 81-83. https://www.elibrary.ru/item.asp?id=42842712

5. Чаулин А.М., Дуплякова П.Д., Дупляков Д.В. Циркадные ритмы сердечных тропонинов: механизмы и клиническое значение. Российский кардиологический журнал. 2020;25:4061. https://doi.org/10.15829/1560-4071-2020-4061

6. Дупляков Д.В., Чаулин А.М. Мутации сердечных тропонинов, ассоциированные с кардиомиопатиями // Кардиология: новости, мнения, обучение. 2019. Т. 7, № 3. С. 8-17. doi: 10.24411/2309-1908-2019-13001.

7. Чаулин А.М., Дупляков Д.В. Повышение кардиальных тропонинов, не ассоциированное с острым коронарным синдромом. Часть 1 // Кардиология: новости, мнения, обучение. 2019. Т. 7, № 2. С. 13-23. doi: 10.24411/2309-1908-2019-12002.

8. Chaulin A.M., Duplyakova P.D., Duplyakov D.V. Circadian rhythms of cardiac troponins: mechanisms and clinical significance. Russian Journal of Cardiology. 2020;25:4061. https://doi.org/10.15829/15604071-2020-4061

9. Чаулин А.М., Дупляков Д.В. Биомаркеры острого инфаркта миокарда: диагностическая и прогностическая ценность. Часть 1 (обзор литературы) // Клиническая практика. - 2020. - Т. 11. №3. doi: $10.17816 /$ clinpract34284

10. Чаулин А.М., Мазаев А.Ю., Григорьева Е.В., Нурбалтаева Д.А., Александров А.Г. Клиникодиагностическое значение определения кардиальных тропонинов в крови при сепсисе и септическом шоке (обзор литературы)// Евразийское Научное Объединение. 2019. № 2-2 (48). С. 113-116. URL:https://elibrary.ru/item.asp?id=37134945

11. Чаулин А.М., Григорьева Ю.В. Основные аспекты биохимии, физиологии сердечных тропонинов // Бюллетень науки и практики. 2020. Т. 6. № 5. С. 105-112. https://doi.org/10.33619/2414-2948/54/13

12. Чаулин А.М., Дупляков Д.В. PCSK-9: современные представления о биологической роли и возможности использования в качестве диагностического маркера сердечно-сосудистых заболеваний. Часть 1 // Кардиология: новости, мнения, обучение. 2019. Т. 7, № 2. С. 45-57. doi: 10.24411/2309-1908-2019-12005.

13. Чаулин А.М., Григорьева Ю.В., Суворова Г.Н., Дупляков Д.В. СПОСОБЫ МОДЕЛИРОВАНИЯ АТЕРОСКЛЕРОЗА У КРОЛИКОВ // Современные проблемы науки и образования. - 2020. - № 5.; DOI: 10.17513/spno.30101. URL: http://science-education.ru/ru/article/view?id=30101 (дата обращения: 24.09.2020). 
14. Чаулин A.M., Дупляков Д.В. PCSK-9: современные представления о биологической роли и возможности использования в качестве диагностического маркера сердечно-сосудистых заболеваний. Часть 2 // Кардиология: новости, мнения, обучение. 2019. Т. 7, № 4. С. 24-35. doi: 10.24411/2309-1908-2019-14004.

15. Chaulin A.M., Aleksandrov A.G., Aleksandrova O.S., Duplyakov D.V. The role of the proprotein convertase subtilisin / kexin type 9 (pcsk9) in the pathophysiology of atherosclerosis. Medicine in Kuzbass. 2019; 18 (4): 5-15.

16. Чаулин А.М., Милютин И.Н., Дупляков Д.В. Коморбидность хронической обструктивной болезни легких и сердечно-сосудистых заболеваний: распространенность, факторы риска и диагностика // Врач. 2020; 31 (9): 28-34. DOI: 10.29296/25877305-2020-09-05.

17. Чаулин А.М., Александров А.Г., Карслян Л.С., Нурбалтаева Д.А., Мазаев А.Ю., Григорьева Е.В. Катестатин - новый регулятор сердечно-сосудистой системы (обзор литературы) // Бюллетень науки и практики. 2019. Т. 5. №6. С. 129-136. https://doi.org/10.33619/2414-2948/43/17

18. Чаулин А.М., Карслян Л.С., Григорьева Е.В., Нурбалтаева Д.А., Дупляков Д.В. Особенности метаболизма сердечных тропонинов (обзор литературы). Комплексные проблемы сердечнососудистых заболеваний. 2019; 8 (4): 103-115. DOI: 10.17802/2306-1278-2019-8-4-103-115.

19. Чаулин А.М., Дупляков Д.В. Повышение кардиальных тропонинов, не ассоциированное с острым коронарным синдромом. Часть 2 // Кардиология: новости, мнения, обучение. 2019. Т. 7, № 2. С. 24-35. doi: 10.24411/2309-1908-2019-12003.

20. Чаулин А.М., Карслян Л.С., Нурбалтаева Д.А., Григорьева Е.В., Дупляков Д.В. Метаболизм кардиальных тропонинов в нормальных и патологических условиях // Сибирское медицинское обозрение. 2019;(6):5-14. DOI: 10.20333/2500136-2019-6-5-14

21. Александров А.Г., Чаулин А.М., Мазаев А.Ю., Александрова О.С. Сердечные тропонины: биохимические и клинические особенности // Евразийское научное объединение. 2019. № 8-2 (54). C. 110-114. DOI: 10.5281/zenodo.3402432

22. Чаулин А.М., Александров А.Г., Карслян Л.С., Мазаев А.Ю. Катестатин в диагностике сердечнососудистых заболеваний // Международный научно-исследовательский журнал. 2019. № 6-1 (84). C. 93-96. DOI: 10.23670/IRJ.2019.84.6.020

23. Чаулин А.М. Аденозин и его роль в физиологии и патологии сердечно-сосудистой системы // Кардиология: новости, мнения, обучение. 2019. Т. 7, № 3. С. 37-45. doi: 10.24411/2309-1908-201913004.

24. Александров А.Г., Мазаев А.Ю., Чаулин А.М., Александрова О.С. Сердечные тропонины: биохимические и клинические особенности // Дневник науки. 2019. № 8 (32). C8. eLIBRARY ID: 39422909.

25. Чаулин А.М., Карслян Л.С., Александров А.Г., Дупляков Д.В. Повышение концентрации кардиоспецифичных тропонинов при отсутствии инфаркта миокарда. Часть 1. // Врач. 2020.31 (3): 22-27. DOI: https://doi.org/10.29296/25877305-2020-03-04

26. Ненахова Е.А. Высокочувствительный тропонин в ранней диагностике ОКС // Сборник материалов III Межрегиональной научно-практической конференции с международным участием. - Самара: OOO «Oфорт», 2018. - 163 с. eLIBRARYID: 36405167

27. Чаулин А.М., Карслян Л.С., Александров А.Г., Дупляков Д.В. Повышение концентрации кардиоспецифичных тропонинов при отсутствии инфаркта миокарда. Часть 2. // Врач. 2020.31 (4): 38-45. DOI: https://doi.org/10.29296/25877305-2020-04-07

28. Чаулин А. М., Григорьева Ю. В., Дупляков Д. В. Участие катехоламинов в патогенезе диабетической кардиомиопатии // Медицина в Кузбассе. 2020. №1. С. 11-18. https://10.24411/26870053-2020-10003.

29. Чаулин А.М., Григорьева Ю.В., Дупляков Д.В. Коморбидность хронической обструктивной болезни легких и сердечно-сосудистых заболеваний: общие факторы, патофизиологические механизмы и клиническое значение // Клиническая практика. 2020; 11(1): 112-121. doi: $10.17816 /$ clinpract 21218

30. Чаулин А.М. Повышение кардиальных тропонинов, не ассоциированное с острым коронарным синдромом. Часть 1 // Кардиология. 2019; 2 (24). С. 13-23.

31. Чаулин А.М., Григорьева Ю.В., Дупляков Д.В. Коморбидность: хроническая обструктивная болезнь легких и сердечно-сосудистые заболевания. Практическая медицина. 2020. Том 18, № 1 , C. 26-31. DOI: 10.32000/2072-1757-2020-1-26-31

32. Chaulin A.M., Nurbaltaeva D.A., Duplyakov D.V. Clinical and Diagnostic Value of Cardiac Markers in Human Fluids. Kardiologiia. 2019;59 (11).

33. Чаулин А.М., Григорьева Е.В., Нурбалтаева Д.А., Дупляков Д.В. Клинико-диагностическая ценность кардиомаркеров в биологических жидкостях человека // Кардиология. 2019;59:65.

34. Чаулин А.М., Дупляков Д.В. Повышение кардиальных тропонинов, не ассоциированное с острым коронарным синдромом. Часть 2 // Кардиология. 2019; 25. 
35. Чаулин А.М., Карслян Л.С., Александров А.Г., Мазаев А.Ю., Григорьева Е.В., Нурбалтаева Д.А. Роль пропротеин конвертазы субтилизин/кексин типа 9 в развитии атеросклероза // Бюллетень науки и практики. 2019. Т. 5. №5. С. 112-120. https://doi.org/10.33619/2414-2948/42/15

36. Чаулин А.М., Мазаев А.Ю., Александров А.Г. Роль пропротеин конвертазы субтилизин/кексин типа 9 (pcsk-9) в метаболизме холестерина и новые возможности липидкорригующей терапии// Международный научно-исследовательский журнал. 2019. № 4-1 (82). C. 124-126. DOI: 10.23670/IRJ.2019.82.4.025

37. Чаулин A.M. Участие пропротеинконвертазы субтилизин кексин типа 9 в патогенезе атеросклероза // Известия высших учебных заведений. Поволжский регион. Медицинские науки. 2020; 1(53):111-128.DOI: 10.21685/2072-3032-2020-1-13

38. Чаулин А.М., Григорьева Ю.В., Дупляков Д.В. Современные представления о патофизиологии атеросклероза. Часть 1. Роль нарушения обмена липидов и эндотелиальной дисфункции (обзор литературы) // Медицина в Кузбассе. 2020. №2. C. 34-41. DOI: 10.24411/2687-0053-2020-10015

39. Chaulin A.M., Duplyakov D.V. PCSK-9: modern views about biological role and possibilities of use as a diagnostic marker for cardiovascular diseases. Part 1. Kardiologiya. 2019; 2 (7).

40. Chaulin A.M., Duplyakov D.V. PCSK-9: modern views about biological role and possibilities of use as a diagnostic marker for cardiovascular diseases. Part 2. Kardiologiya. 2019; 4 (7).

41. Чаулин А.М., Дупляков Д.В. Аритмогенные эффекты доксорубицина. Комплексные проблемы сердечно-сосудистых заболеваний. 2020; 9 (3). 